\title{
Neutronic modeling of a subcritical system with corium particles and water (from international benchmark)*
}

\author{
Anton D. Smirnov ${ }^{1}$, Ekaterina V. Bogdanova ${ }^{1}$, Pavel A. Pugachev ${ }^{1}$, Ivan S. Saldikov ${ }^{1}$, \\ Mikhail Yu. Ternovykh ${ }^{1}$, Georgy V. Tikhomirov ${ }^{1}$, Hiroki Takezawa ${ }^{2}$, Takeshi Muramoto ${ }^{3}$, \\ Jun Nishiyama ${ }^{3}$, Toru Obara ${ }^{3}$ \\ 1 Institute of Nuclear Physics and Engineering, National Research Nuclear University MEPhI, 31 Kashirskoye Hwy, Moscow 115409, Russian \\ Federation \\ 2 Department of Nuclear Safety Engineering, Faculty of Science and Engineering, Tokyo City University, 1-28-1 Tamazutsumi, Setagaya-ku, Tokyo \\ 158-8557, Japan \\ 3 Laboratory for Advanced Nuclear Energy, Institute of Innovative Research, Tokyo Institute of Technology, 2-12-1-N1-19 Ookayama, Meguro-ku, \\ Tokyo 152-8550, Japan
}

Corresponding author: Anton D. Smirnov (ADSmirnov@mephi.ru)

Academic editor: Yury Kazansky • Received 6 May 2020 • Accepted 20 August 2020 • Published 16 September 2020

Citation: Smirnov AD, Bogdanova EV, Pugachev PA, Saldikov IS, Ternovykh MYu, Tikhomirov GV, Takezawa H, Muramoto T, Nishiyama J, Obara T (2020) Neutronic modeling of a subcritical system with corium particles and water (from international benchmark). Nuclear Energy and Technology 6(3): 155-160. https://doi.org/10.3897/nucet.6.57742

\begin{abstract}
After the accident at the Fukushima Daiichi NPP, the attention of the scientific community is riveted on how the consequences are being eliminated. Removing corium - a lava-like resolidified mixture of nuclear fuel with other structural elements of the reactor - remains the most difficult task, the solution of which can take several decades. It is extremely important to exclude the occurrence of any emergency processes during the removal of corium. The purpose of this work was to solve a coordinated hydrodynamic and neutronic problem characterized by a large number of randomly oriented and irregularly located corium particles in water as part of the development of a benchmark for this class of problems. Monte Carlo-based precision codes were used to perform a neutronic analysis. The positions of corium particles were determined from the numerical simulation results. The analysis results obtained using the codes involved showed good agreement for all the states considered. It was shown that the modern neutronic codes based on the Monte Carlo method successfully cope with the geometric formation and solution of the problem with a nontrivial distribution of corium particles in water. The results of the study can be used to justify the safety of corium handling procedures, including its extraction from a damaged power unit.
\end{abstract}

\section{Keywords}

Nuclear safety, beyond-design-basis accident, nuclear fuel extraction, MCU, MVP, SERPENT

* Russian text published: Izvestiya vuzov. Yadernaya Energetika (ISSN 0204-3327), 2020, n. 2, pp. 135-145. 


\section{Introduction}

The Fukushima Daiichi nuclear disaster (11 March 2011) received the Level 7 (Major Accident) on the International Nuclear Event Scale. As a result of the accident, the core melted and to form corium. Corium is a lava-like alloy of the contents of a nuclear reactor, consisting of a mixture of nuclear fuel with concrete, metal structural elements and other things, which is formed as a result of the melting of the core and the reactor vessel. In order to ensure safety during the elimination of the consequences of the accident at the Fukushima I NPP, it is important to prevent a possible emergency during the planned removal of the solidified corium.

In 2018, Tokyo Electric Power Company (TEPCO) published photographs of the pedestal bottom of Fukushima I-2 showing objects that look like stones, which may be fuel fragments (Robot 2020). The detected objects have different sizes and structures. According to the IRID (International Research Institute for Nuclear Decommissioning) plan, large corium pieces will be broken into small pieces prior to their removal. Small corium particles will be removed from the pedestal for further storage in containers. The corium is currently being cooled with water. When corium is extracted, the ratio of solidified nuclear fuel to water can change. If, in the course of the work performed, as a result of random events, solidified corium finds its way into water, then it will approach to or may achieve re-criticality. The purpose of our work was to conduct a high-precision assessment of the criticality of solidified corium in some realistically possible states to justify nuclear safety.

The paper presents the results of the first stage of a joint Russian-Japanese study on the neutronic properties of systems with corium particles in water. At the next stages, it is planned to consider systems with an external neutron source and critical systems with a large number of corium particles in water.

\section{Determining the corium isotopic composition}

When developing possible scenarios for the occurrence of critical states of a water-corium mixture, it is necessary to take into account a number of uncertainties. A criticality analysis of solidified corium requires data on the history of the reactor operation prior to the accident, the fuel isotopic composition of different types of fuel assemblies at the time of the accident, the reactor design features, and the course of the accident. When assessing the state of irradiated fuel at the time of the accident, it is possible to use the approaches described in (Baranov et al. 2008, Kryuchkov et al. 2004). All the reactors at the Fukushima I NPP are boiling water reactors (BWR), which is the second most common type of electricity-ge- nerating nuclear reactors after the pressurized water reactors (PWR). The reactors are of the direct-cycle type, i.e. steam generation in them occurs directly in the core itself. Demineralized water is used as a coolant and neutron moderator - it is in the reactor core at a pressure of about $7.6 \mathrm{MPa}$. At this pressure, the cooling water boils in the core at a temperature of $285^{\circ} \mathrm{C}$. When modeling the fuel composition in the corium, one has to take into account the significant unevenness of fuel burnup along the height of the fuel assemblies associated with the reactor design (Albrek et al. 2018, Hashlamoun et al. 2019). The most detailed descriptions of the design and isotopic composition of the fuel assemblies at the Fukushima I NPP are presented in the OECD/NEA benchmark (Burnup Credit 2012).

It should be especially noted that at the moment not only the composition of the fuel melt and structural materials is unknown, but also its distribution over the reactor room (Darnowski et al. 2016). Therefore, the development of a melt model is greatly complicated by its verification based on experimental data. Studies carried out at the Fukushima I-1 show that almost all of the corium is located in the sub-reactor room (List of Documents 2012), and only a small part of it remains inside the reactor shell and a part is inside the containment. All the structural materials of the core were melted and became part of the corium. This facilitates the corium modeling due to the lack of great heterogeneity. The homogeneity of the corium composition is an approximation; however, it allows an analysis based on a conservative approach.

The available data make it possible to separate the corium models into the corium inside the reactor shell and the corium in the sub-reactor room. The emergency scenario selected for a neutronic analysis is based on the results of studies of emergency power units. Inside the power units, where the accident occurred, special devices were lowered for visual analysis of what was happening. However, due to a very high level of radiation conditions, limited maneuverability, and inaccessibility of space, these devices cannot obtain a complete picture of the reactor room being examined. Because of this, there are only abrupt data on the real situation inside the rooms with the melted fuel and structural materials (Burnup Credit 2015). It is known that different materials, and most importantly, their combination, have different melting points. Attention should also be paid to various states of aggregation: melted $\mathrm{UO}_{2}$ is at the top, $\mathrm{ZrO}_{2}$ is slightly lower. However, at a temperature of $2600{ }^{\circ} \mathrm{C}$ a ceramic melt U-Zr-O is formed. At $2400{ }^{\circ} \mathrm{C}$, the melt can contain alpha- $\mathrm{Zr}(\mathrm{O})-\mathrm{UO}_{2}$ and monotectic $\mathrm{U}-\mathrm{UO}_{2}$. The rods of a burnable absorber made of $\mathrm{Al}_{2} \mathrm{O}_{3}+\mathrm{B}_{4} \mathrm{C}$ melt at the same temperature $\left(2050{ }^{\circ} \mathrm{C}\right)$, and $\mathrm{B}_{4} \mathrm{C}$ itself melts at a temperature of $2350{ }^{\circ} \mathrm{C}$. A mixture of $70 \%$ fresh fuel and $30 \%$ structural materials and concrete can be considered a conservative assessment of the corium state in terms of the occurrence of criticality. 


\section{Approaches to neutronic modeling of systems with corium}

Corium re-criticality is the main hazard when handling nuclear fuel residues in the damaged units of the $\mathrm{Fu}$ kushima I NPP. A number of studies are focused on this problem and many approaches and software tools have been used in the framework of these works.

A group of scientists from the Warsaw University of Technology studied the likelihood of re-criticality formation as a result of flooding Fukushima I-3 (Darnowski et al. 2017). Neutronic simulations were performed using the SERPENT Monte Carlo code. A three-dimensional model of four fuel assemblies was taken as a basis. The MELCOR computer code (Fernandez-Moguel and Birchley 2015) was used to simulate the development of an accident. Calculations have shown that re-criticality may occur even when a small part of the core is flooded and with a simultaneous failure of the borated water injection and heat removal systems.

Researchers at the University of Stuttgart are currently studying the effect of the corium model used in neutronic analysis of corium-water systems on the calculation results (Freiría López et al. 2018, 2019). In their works, they compare the homogeneous, heterogeneous-network and heterogeneous model with a random distribution of corium particles with the abstract most reliable computational model. The scientists varied particle sizes and porosity to determine the best model in terms of accuracy, structural complexity, and computational capacity requirements. In their calculations, the scientists used the Monte Carlo-based codes, SERPENT and MCNP, and the infinite neutron multiplication factor was the main functional for comparison.

The scientists at the Tokyo Institute of Technology (the authors of this article) are modeling dynamic transients in corium-water systems, including the penetration of corium into water during the extraction of radioactive particles. In their calculations, the scientists use a self-developed integral kinetic code, MIK, the accuracy of the solutions of which was verified and presented in (Tuya and Obara 2018). In 2020, the researchers of the Institute published a paper with an assessment of the radiation doses caused by emergency processes during the corium handling procedures (Fukuda et al. 2020).

In addition to the computational methods for determining the nuclear properties of corium, after the accident at the Fukushima I NPP, the number of experimental installations simulating corium and its interaction with other objects has increased. The most interesting and complete reviews of this line of research in corium include recent articles written by scientists from Japan (Gunji et al. 2017) and France (Chikhi et al. 2017). In their research works, the scientists, using substances that replace corium, studied the interaction of nuclear fuel particles with water and structural materials.

\section{Methods and tools}

Test problem system

Various situations of the formation of suspended corium particles in water are considered. Such situations may occur, firstly, when a part of the corium inside the reactor shell crumbles as a result of its cracking and penetrating into the water in the sub-reactor room, which is currently used to cool the corium, and, secondly, during works on removing the corium from the sub-reactor room, after remote crushing into a form suitable for its removal. The situations described have a number of uncertainties in the geometry of the corium in water, namely: in the volume of the corium, in the size and geometry of the particles, in the state of the uranium-water mixture.

This paper presents a system of test problems, which includes two scenarios and several states within each of them. Scenario 1 is an interpretation of the process of falling corium particles into water, for example, as a result of an accident while the corium was removed from a damaged power unit. According to this scenario, 1000 cubic particles of corium $1 \mathrm{~cm}^{3}$ in volume fall into the water from State 1 into State 5 (Fig. 1). In total, Scenario 1 includes five states, each of which corresponds to a specific time point in the range from 0 to $0.8 \mathrm{~s}$. The volume of the particles and the pitch of their placement at the initial moment of time correspond to the maximum value of the multiplication factor of the infinite lattice of corium particles in water.

To determine the positions of the particles, a hydrodynamic numerical simulation was carried out in a CFD code based on the moving particle semi-implicit (MPS) method using Particleworks software (Particleworks Europe 2020). At the starting point of the calculation, 1000 cubic particles with a side of $10 \mathrm{~mm}$ each were dropped into a cylindrical volume of water with a height of $150 \mathrm{~mm}$. Further, the position of each cube was calculated and recorded in the output file of the program up to the moment when all the cubes descended to the bottom of the cylinder with water at a time point of 0.8 seconds. Five states were selected for transmission to the neutronic calculation, corresponding to the time points of $0,0.1,0.2,0.4$, and 0.8 seconds (see Fig. 1). More details about the conditions of hydrodynamic modeling can be found in (Muramoto et al. 2019).

It should be noted that Scenario 1 is a deeply subcritical task, the purpose of which is to study the methods of geometric formation and solution of such a non-trivial problem by codes based on the Monte Carlo method, taking into account all the limitations inherent in the subcritical problem.

Scenario 2 has one important difference from Scenario 1 , namely, the corium particles fall not on the concrete bottom but on the corium bed (Fig. 2). Thus, the system can exhibit inhomogeneity of physical properties and inaccessibility of some parts of the system for neutrons generated in other parts of the system. This may require non-standard approaches when the Monte Carlo method is used (Kalugin and Tebin 2015). 


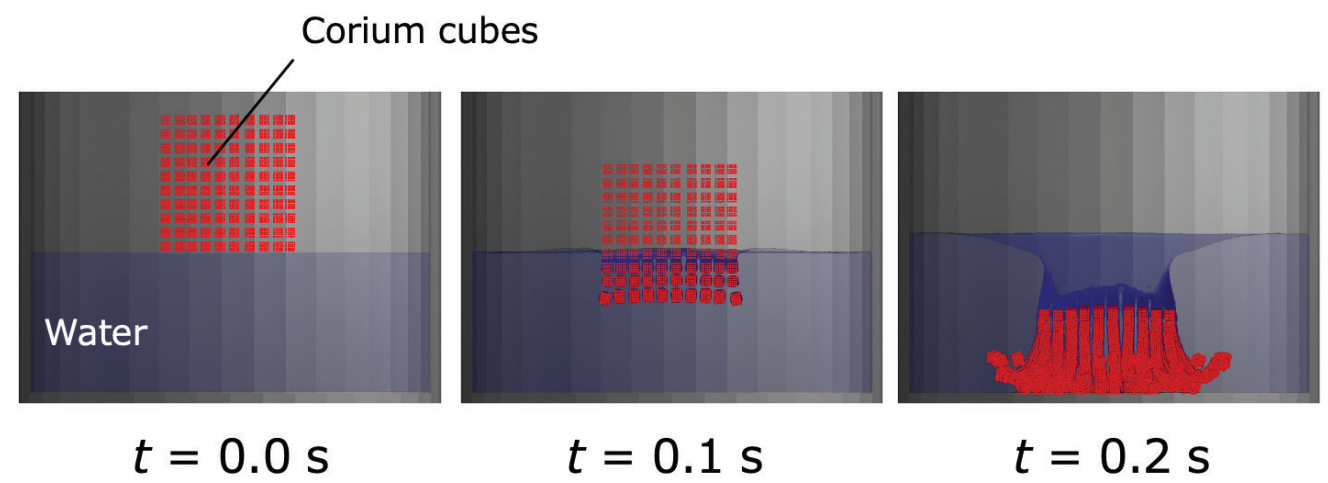

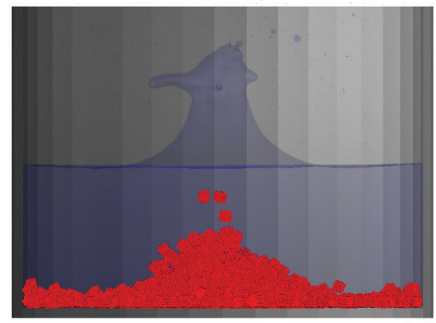

$t=0.4 \mathrm{~s}$

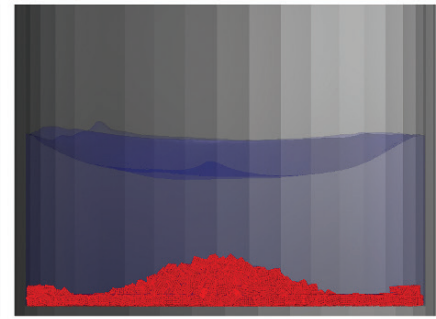

$t=0.8 \mathrm{~s}$

Figure 1. Simulated states of the water-corium system from Scenario 1 of the test problem system.

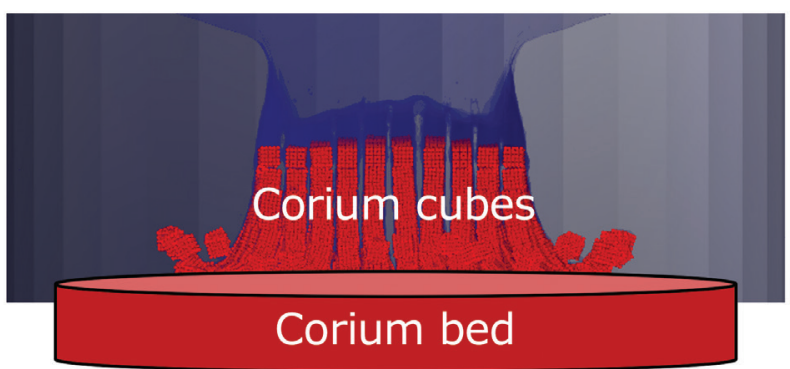

Figure 2. Schematic representation of the state of the water-corium system with a corium bed from Scenario 2 of the test problem system.

In our work, only the calculation results for Scenario 1 are presented. The simulation results for Scenario 2 will be presented in subsequent publications. The test problem system is the basis of an international benchmark, the publication of which is planned for the final part of joint work.

\section{Neutronic codes}

Neutronic calculations were carried out by the Russian-Japanese team using the Russian MCU code (Oleynik 2015), the SERPENT program (Leppänen et al. 2015) developed at the Technical Research Center of Finland, and the Japanese MVP code (MVP/GMVP 2017) developed at the Japan Atomic Energy Agency (JAEA). All these codes are based on the Monte Carlo method and simulate neutron transport.
All calculations were performed using the Evaluated Nuclear Data Library ENDF-B/7.0. The number of batches and the number of histories in the batch were chosen so that the accuracy of calculations corresponded to the standard deviation for $K_{\text {eff }}<0.02 \%$.

\section{Results and discussion}

The performed studies have shown good agreement in the calculation of the multiplication factor between the SERPENT and MVP codes. The maximum deviation between SERPENT and MVP of $0.18 \%$ corresponds to the state with the lowest multiplication factor at a time point of 0.0 s. The deviations between MCU and the other codes can be associated with different approaches when the process of neutron thermalization is taken into account.

At this stage, the geometry formation technology was tried out and the codes and their constant support were cross-verified for a coordinated hydrodynamic and neutronic problem characterized by a large number of arbitrarily oriented and irregularly located corium particles. To formulate the final version of the benchmark, it is proposed to consider two directions of modernization: (1) calculations of radiation sources in a problem with an external source and (2) selection of the geometry of models with a reasonable number of corium particles for calculations and a multiplication factor of more than 0.95 . Such tasks are relevant for assessing the criticality and analyzing the radiation situation during the corium handling procedures. 


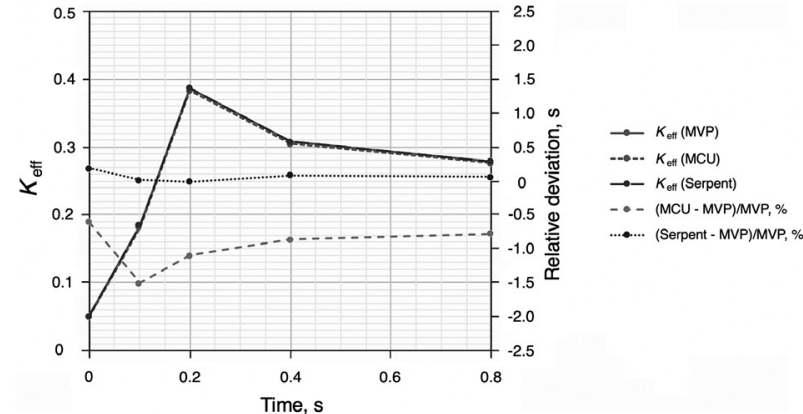

Figure 3. Results of calculating the neutron multiplication factor.

\section{Conclusion}

Justifying nuclear safety, when handling corium, is an important and non-trivial task. Such systems with corium particles are intrinsically subject to considerable uncertainty. Due to the high level of radiation conditions, currently there are only abrupt data on the real situation inside the rooms with the melted fuel and structural materials. Therefore, it is important to choose the correct computational model of the corium for a neutronic analysis of the system.
The paper considered situations of placing 1000 cubic corium particles in the water of the sub-reactor room. Hydrodynamic numerical modeling was carried out in relation to the position of the cubes from the moment they fell into the water layer until they sank to the concrete base. The data obtained were used to generate input files for the neutronic analysis codes. Good agreement in the results between the codes for all the considered states was shown.

The implemented technique for solving a coordinated hydrodynamic and neutronic problem can be used to substantiate the safety of procedures for handling corium, including its removal from a damaged power unit. The benchmark developed in this work can be used for creating new software tools.

MEPhI was financially supported by the Ministry of Science and Higher Education of the Russian Federation (unique identifier of the project RFMEFI61419X0003). Tokyo Tech and TCU were financially supported by the Nuclear Energy Science \& Technology and Human Resource Development Project (through concentrating wisdom) from the Japan Atomic Energy Agency / Collaborative Laboratories for Advanced Decommissioning Science.

\section{References}

- Albrek MM, Ternovykh MY, Shorov VY (2018) Influence of accounting the distribution parameters of the fuel assembly (FA) and dynamic operating characteristics on the fuel nuclide composition of a VVER-1000 spent fuel assembly (SFA). Journal of Physics: Conference Series 1133: 012008. https://doi.org/10.1088/17426596/1133/1/012008

- Baranov VG, Ternovykh MY, Tikhomirov GV, Khlunov AV (2008) Simulation of nuclear-physical processes in the surface layer of a fuel kernel with a consumable absorber. At. Energy 105(6): 391396. https://doi.org/10.1007/s10512-009-9113-6

- Burnup Credit Criticality Benchmark Phase IIIC - Nuclide Composition and Neutron Multiplication Factor of BWR Spent Fuel Assembly for Burnup Credit and Criticality Control of Damaged Nuclear Fuel (2012) OECD, 184 pp.

- Burnup Credit Criticality Safety Benchmark Phase III-c (2015) Tech. Rep. OECD, 255 pp.

- Chikhi N, Fichot F, Swaidan A (2017) Effect of water entrainment on the coolability of a debris bed surrounded by a by-pass: Integral reflood experiments and modelling. Annals of Nuclear Energy 110 418-437. https://doi.org/10.1016/j.anucene.2017.06.033

- Darnowski P, Potapczyk K, Gatkowski M, Niewinski G (2016) Development of One-way-coupling Methodology between Severe Accident Integral Code MELCOR and Monte Carlo Neutron Transport Code SERPENT. Procedia Engineering 157: 207-213. https://doi org/10.1016/j.proeng.2016.08.358

- Darnowski P, Potapczyk K, Swirski K (2017) Investigation of the recriticality potential during reflooding phase of Fukushima Daiichi Unit-3 accident. Annals of Nuclear Energy 99: 495-509. https://doi. org/10.1016/j.anucene.2016.10.004
Fernandez-Moguel L, Birchley J (2015) Analysis of the accident in the Fukushima Daiichi nuclear power station Unit 3 with MELCOR_2.1. Annals of Nuclear Energy 83: 193-215. https://doi. org/10.1016/j.anucene.2015.04.021

- Freiría López M, Buck M, Starflinger J (2018) A Criticality Evaluation of Fukushima Daiichi Unit 1 Fuel Debris. Volume 9: Student Paper Competition. American Society of Mechanical Engineers. https://doi.org/10.1115/ICONE26-81148

- Freiría López M, Buck M, Starflinger J (2019) Neutronic modeling of debris beds for a criticality evaluation. Annals of Nuclear Energy 130: 164-172. https://doi.org/10.1016/j.anucene.2019.02.034

- Fukuda K, Tuya D, Nishiyama J, Obara T (2020) Radiation Dose Analysis in Criticality Accident of Fuel Debris in Water. Nuclear Science and Engineering 194(3): 181-189. https://oi.org/10.1080/ 00295639.2019.1665459

- Gunji S, Tonoike K, Izawa K, Sono H (2017) Study of experimental core configuration of the modified STACY for measurement of criticality characteristics of fuel debris. Progress in Nuclear Energy 101: 321-328. https://doi.org/10.1016/j.pnucene.2017.03.002

- Hashlamoun TM, Vygovsky SB, Leskin ST, Duman AS (2019) Determination of 18-month fuel cycle parameters for the purpose of fuel costs minimization at the basis of use constructions of fuel assemblies in VVER-1200 reactors. Nuclear Energy and Technology 5(1): 9-15. https://doi.org/10.3897/nucet.5.33976

- Kalugin AV, Tebin VV (2015) Criticality Calculations of Non-Ordinary Systems. VANT. Ser. Fizika Yadernykh Reaktorov [VANT. Series: Nuclear Reactor Physics] 5: 4-17. [in Russian]

- Kryuchkov EF, Ternovykh MY, Tikhomirov GV, Li C, Shmelev AN, Saito M (2004) Deep Burnup High burnup fuel cycles: reactivity co- 
efficients analysis. Novosti Vysshykh Uchebnykh Zavedeniy. Yadernaya Energetika [News of Higher Educational Institutions. Nuclear Energy] 3: 73-78. [in Russian]

- Leppänen J, Pusa M, Viitanen T, Valtavirta V, Kaltiaisenaho T (2015) The SERPENT Monte Carlo code: Status, development and applications in 2013. Annals of Nuclear Energy 82: 142-150. https://doi. org/10.1016/j.anucene.2014.08.024

- List of Documents concerning the Response Status at Fukushima Daiichi Nuclear Power Station and Fukushima Daini Nuclear Power Station (2012) TEPCO, 186 pp.

- Muramoto T, Nishiyama J, Obara T (2019) Numerical analysis of criticality of fuel debris falling in water. Annals of Nuclear Energy 131: 112-122. https://doi.org/10.1016/j.anucene.2019.03.005

- MVP/GMVP version 3: General purpose Monte Carlo codes for neutron and photon transport calculations based on continuous energy and multigroup methods (2017) JAEA, $446 \mathrm{pp}$.
- Oleynik DS (2015) The Monte Carlo estimation of an effect of uncertainties in initial data on solving the transport equation by means of the MCU code. Physics of Atomic Nuclei, Maik Nauka-Interperiodica Publishing, 78(11): 1194-1199. https://doi.org/10.1134/ S1063778815110149

- Particleworks Europe (2020) Particleworks Europe. http://www.particleworks-europe.com/ [accessed 03.05.2020]

- Robot squeezes suspected nuclear fuel debris in Fukushima reactor. The Verge. https://www.theverge.com/2019/2/15/18225233/robot-nuclear-fuel-debris-fukushima-reactor-japan [accessed 03.05.2020]

- Tuya D, Obara T (2018) Supercritical transient analysis in hypothetical fuel-debris systems by multi-region approach based on integral kinetic model. Annals of Nuclear Energy 120: 169-177. https://doi. org/10.1016/j.anucene.2018.05.033 